\title{
EXPERIMENTAL AND NUMERICAL ANALYSIS OF REINFORCED STONE BLOCK MASONRY BEAMS USING GFRP REINFORCEMENT
}

\author{
Ines Fayala*1, Oualid Limam², Ioannis Stefanou ${ }^{3}$ \\ 1,2 Université de Tunis El Manar, Ecole Nationale d’Ingénieurs de Tunis, Laboratoire de Génie Civil, BP 37 le Belvédère 1002 , \\ Tunis, Tunisia. \\ ${ }^{3}$ Université Paris-Est, Laboratoire Navier (École des Ponts Paris Tech, IFSTTAR, CNRS), École des Ponts Paris Tech, 6 et 8 avenue \\ Blaise Pascal, 77455, Marne-la-Vallée cedex 2, France
}

\section{Introduction}

Natural stone structures represent the largest part of the construction heritage in the world such as bridges, civil and worship buildings or historical monuments. The natural stone is preferred for many reasons such as beauty, accessibility, hardness, durability, strength and sustainability.

It is necessary to have a good understanding of the mechanical behaviour of stone structures. Their main characteristics are a high compressive strength and an almost null tensile strength due to the joints. Therefore, in historical structures, the use of stone is mostly restricted to members mainly working in compression (piers, arches, walls and vaults) [1].

Most historical buildings are built with masonry and it's well known that they are inadequately reinforced or unreinforced and pose a major seismic hazard in areas if they are not correctly designed. This heritage is accumulating damage due to deterioration of materials, repeated loading and exceptional events like earthquakes. Their preservation is a fundamental issue in the cultural life of modern societies by repairing and strengthening. In Tunisia, there are many masonry monuments damaged as for example, the Roman amphitheater of "El Jem" dating from the 3rd century which presents stone deterioration and many structural cracks in the vaults and the "Ribat" of Monastir damaged by the earthquake in October 2013 (Fig.1)

The reinforcement of masonry structures is one of the most frequently used practices in restoration of historical buildings in the purpose to enhance the resistance. It can be performed using steel bars, rings and/or composite materials [2] especially in seismic areas [3, 4]. In the last two decades, composite materials, as FRP [5], have been increasingly considered for strengthening and repairing both modern and historic masonry constructions. FRP are excellent candidates for strengthening because of the high tensile strength they provide, their resistance in corrosion and in their easy handling. Several papers have addressed the strengthening of masonry with carbon and glass fibers reinforced composites [6-11] in the purpose to increase their ultimate capacity (strength and ductility).

In the beginning, FRP were used for the reinforcement of concrete structures. FRP consist of high strength fibres embedded in a resin matrix. The fibres are usually Carbon (CFRP), Glass (GFRP) or Aramid (AFRP). They are available in sheets, strips, tendons, reinforcing bars. The available literature related to their use either as an internal reinforcement method or as an external strengthening method for reinforced concrete structural members is rich [12-15]. The researchers carried out monotonic and cyclic tests on FRP reinforced concrete beams and investigated the effect of FRP reinforcement ratio and strength of concrete on the flexural resistance of the specimens. They concluded that the ultimate moment capacity of the beams increase as the reinforcement ratio increases and tested beams were considered to be safe in terms of deformability.

Most research is done on masonry walls or concrete beams reinforced with industrial composite strips or wraps. Because of their high stiffness, industrial composites, when bonded to masonry produce under loading a strain incompatibility which induces a stress concentration and their premature debonding. We must focus on the specific features of the masonry structures because of the complexity of the monuments' geometry, cracks' causes and the importance of every 
intervention on historical structures. They can be subjected to a local tension under their weight or under horizontal inertial loads induced by a seismic action. When the tensile strength is reached, cracks appear in the planes perpendicular to the principal tensile stress direction.

Starting from extension of approaches proposed for concrete structures, the objective of this paper is to present experimental and numerical tests performed on masonry beams reinforced with economic hand-made GFRP strips which are externally bonded on their tensile face. The externally bonded (EB) technique was preferred to the Near Surface Mounted (NSM) technique because in the latter technique, performing grooves to introduce reinforcements may cause cracking planes through the thickness of the structure.

The used composites are not only a low-cost technology but they present also the mechanical advantage of strain compatibility with masonry with a Young's modulus close to that of masonry but a tensile strength many times higher than the masonry. The choice of spaced strips with predefined shapes presents an advantage relevant to the hygroscopic compatibility in comparison with the wraps. The aesthetic aspect can be a drawback but if it's compared to other alternative technologies, EB strips are in accordance with some ICOMOS recommendations (removability, minimum repair and respect of the original conception, durability and compatibility...) [16]. Furthermore, these composites are available and commonly used in the local small boats industry.

So, in the purpose to assess the tensile performance of masonry strengthened by composite indirectly through the beams flexural testing, eight beams were constructed using stone masonry units and tested in four-point bending with an effective span of $0.824 \mathrm{~m}$ between the supports. These tests intend to reproduce artificially a tensile stress state in a masonry structure and to verify the efficiency of the EB composite strips strengthening technique to increase its bearing capacity by increasing the local tensile strength at its boundary. Load-displacement curves have been produced from recorded data, then a discussion of experimental and numerical results is proposed. The tests are not experimental prototypes of real masonry structures. Our final purpose is the validation of the proposed numerical model on the tested beams to be used for numerical analysis of ancient masonry structures. Numerical models can be used afterwards to compare the behaviors of strengthened and non-strengthened real masonry structures subjected to a local tensile stresses at their boundaries. Concerning the reinforcement of the structure showed in Fig.1, GFRP strips can be used with adapted geometry and bonded externally to the masonry following the principal tensile stresses. In practice, cracks should be repaired first with epoxy injection.

\section{Experimental program}

\subsection{Description of the beams}

The tested specimens consisted of 8 stone masonry beams manufactured according to the sketch of Fig.2. Their average length was $1.024 \mathrm{~m}$ with joints approximately $6 \mathrm{~mm}$ thick. All the tested beams have two courses of stone masonry units. Every beam has been made by 10 prismatic stone blocks (with the dimensions of $100 \mathrm{~mm}$ width, $100 \mathrm{~mm}$ height and $200 \mathrm{~mm}$ length) which were assembled using hydraulic lime mortar joints. Some of the beams were reinforced with GFRP strips at the traction side (Fig.3). After the mortar hardening (28 days), the preparation of the surface for the reinforcement was carried out by sanding and dusting in order to ensure good adhesion between the strip and the stones. The GFRP strips were externally bonded to the masonry beams (see dry assembling in Fig.3b) by using a structural thixotropic glue (sikadur_30), which is a mixture of epoxy resin and special fillers designed for gluing structural reinforcements. Seven days after, the glue reaches a good resistance according to the technical notice. After this period of time, beams were overturned with a kind of formwork in order to be tested in bending. The specimens are classified into four groups as shown in Tab.1: one group was not strengthened and it was kept as a reference and the rest three groups were reinforced externally on the bottom with GFRP strips of different 
thicknesses.

\subsection{Materials properties}

Experimental measures have been carried out to determine the Young's modulus, the compressive strength and the tensile strength of the stone and the mortar as well as the tensile properties of the composite reinforcement. The materials characteristics are summarized in Tab. 2 and Tab. 3 .

\subsubsection{Masonry units}

The masonry units are stone blocks originating from a quarry used for the restoration of "El Jem" amphitheater located in Monastir (Tunisia). The stone blocks were hewed into prismatic specimens with dimensions $(100 \times 100 \times 200 \mathrm{~mm})$ to build beams and $(40 \times 40 \times 160 \mathrm{~mm})$ for testing purposes.

The type of rock is sandstone which is a sedimentary rock. According to the literature [17-19], the Poisson's ratio varies from 0.2 to 0.35 .

The Young's modulus was determined for three cylindrical stone specimens (100 $\mathrm{mm}$ diameter and $200 \mathrm{~mm}$ height) by means of the longitudinal electronic extensometer as illustrated in Fig.4. The extensometer used can measure the deformation of a cylindrical or prismatic specimen. The measuring rod was attached to the test specimen and after adjusting, stop levers were released so that the jaws became free to measure sensors displacements. Cyclic loading tests were carried out on the stone specimens under displacement control at a constant rate of $0.01 \mathrm{~mm} / \mathrm{sec}$ by means of electromechanical compression machine. The maximum force applied is relative to the third of the material compressive strength in order to remain in the elastic range. The average value of Young's modulus was found equal to $17 \pm 0.5 \mathrm{GPa}$ for the stone specimens. The Young's modulus was determined from the strain-stress curve after linear fitting of experimental data (see Fig.5). The Poisson's ratio for the stone was assumed to be 0.2 .

Compressive and flexural strength tests were carried out on three prismatic stone specimens of dimensions $40 \times 40 \times 160 \mathrm{~mm}$ as shown in Fig.6 in accordance with standards tests EN 196-1. The average strength was equal to $8.1 \pm 0.4 \mathrm{MPa}$, corresponding to the peak load under static monotonic loading) and $4.1 \pm 0.1 \mathrm{MPa}$ (obtained by the elastic bending peak tensile stress) for compression and traction respectively (Tab.2).

\subsubsection{Mortar}

The choice of lime mortar is based on its use in almost all historical monuments. A lime to sand ratio (by volume) 1:3 was adopted for this work, according to literature [20] which specifies that the lime mortar encountered in ancient structures has a binder to aggregate ratio ranging between 1:4 and $1: 1$. This ratio is also provided by the document "Specific use of natural hydraulic lime" that complies with specific recommendations of ICOMOS (International Council on Monuments and Sites) [21].

The lime used is an artificial hydraulic lime with strength class 10. A sand equivalent test was performed to verify the good quality of the used sand (SE $=84 \%$ ). The mortar consistency was satisfactory in accordance with standards tests [22-23] performed in order to determine the quantity of mixing water required. Compressive and flexural strength tests carried out on prismatic limebased mortar specimens $(40 \times 40 \times 160 \mathrm{~mm}$ ) gave respectively a mean strength equal to $6.2 \pm 0.3 \mathrm{MPa}$ and 1.8 $\pm 0.2 \mathrm{MPa}$ as shown in Tab. 2 .

The determination of the Young's modulus was made by mean of the same longitudinal electronic extensometer already used previously and following the same procedure (see Fig.7). The average value of Young's modulus found for mortar specimens is $1.2 \pm 0.1 \mathrm{GPa}$ and the Poisson's ratio is assumed equal to 0.3 . 


\subsubsection{GFRP strips}

GFRP strips were used as reinforcement for stone masonry beams. There are three types of strips considered for this study: 2 layers, 3 layers and 4 layers strips. The manufacturing process consists in alternating resin and chopped glass strand mat $\left(450 \mathrm{~g} / \mathrm{m}^{2}\right)$, taking care to release the air bubbles by a roller for every layer (see Fig. 8). Glass support was employed as a working basis so the upper surface (which is the rough one) is the contact surface with the masonry beam. After three days of drying at room temperature, GFRP plates were cut, using a guillotine-shears, into strips $(90 \times 982 \mathrm{~mm})$ for reinforcing and test specimens $(25 \times 250 \mathrm{~mm})$ to determine tensile properties (see Fig.9 for specimens and testing procedure) in accordance with ISO 527-4 [24] as depicted in Fig. 10. The tensile strength is measured in only one direction since the composite is considered as homogeneous material seeing that it was manufactured using a chopped glass strand mat. Tab. 3 summarizes the details of the tested FRP specimens corresponding to the curves drawn in Fig.11 which shows an elastic-brittle behaviour of the composites.

\subsection{Test setup, instrumentation and procedure}

Four-points bending tests were performed on each beam until failure. The experimental setup including the loading and the support arrangement is illustrated in Fig.12. The beams were simply supported by placing rollers in the middle of each end-block which gives an effective span of $0.824 \mathrm{~m}$. When overturned and placed on the supports, beams were, first, subjected naturally to bending under their own weight. Then, the four points bending load test was performed. So, the considered LVDT recorded only beams deflection when they were subjected to four points bending load.

The load was applied via two other steel rollers positioned in the top of the beam in order to apply a line load at $362 \mathrm{~mm}$ from the edge; so that the distance between these two loading steel rollers is $300 \mathrm{~mm}$. The beams were tested monotonically until failure by a displacement controlled electromechanical flexion machine at a constant rate of $0.01 \mathrm{~mm} / \mathrm{sec}$.

The load was applied with a hydraulic jack with a capacity of $150 \mathrm{kN}$ and distributed with a stiff metallic box girder. Data recording was started before the girder is set, so that the load induced by the girder is taken into account.

The instrumentation was set up to measure the deflection at mid-span of the beam. A steel measure device was adopted to facilitate the mid-span deflection measurement. This device is simply placed on the upper side of the beam so that the supports coincide with the beam supports on the bottom. Two linear variable differential transducers (LVDTs) were used to measure the mid-span deflection and set on the both sides of the measure device.

\subsection{Experimental results and discussion}

To illustrate the global behaviour of the beams, the average load-deflection curves of the tested beams are presented in Fig.13. A variance in the results is observed between two similar tested beams. The experimental scatter seems to be due to the manual manufacturing methodology of the masonry. In fact, for the tested beams, the peak load increases from $3 \mathrm{kN}$ for the un-reinforced beams to a peak load ranging from $10 \mathrm{kN}$ (for the beam B 2-1 strengthened with 2 layers) to $14 \mathrm{kN}$ (for the beam B 4-2 strengthened with 4 layers).

Furthermore, in order to visualize the experimental tendency, four average curves are depicted in Fig.13 corresponding to two similar specimens each. As it can be noted in this figure, the experimental initial stiffness doesn't follow the expected increasing when the number of layers increases. Theoretically, when bonding thin strips having a Young's modulus E $=6 \mathrm{GPa}$ close to the masonry one, the second moment of area should increase slightly which is followed by a small increasing of the initial stiffness. This small increasing is not detected automatically by the tests when 
the number of layers increases. However, the average curves (Fig.13) show a tendency of the initial stiffness increasing within the strengthening and, as expected, the beams behave globally in a very similar way in the intial elastic part. In particular, Figure 14 shows the failure modes of masonry beams. Fig. 14a shows the failure mode of unreinforced beam: it is a bending mode which results in a vertical split at mid-span. Figures 14b, 14c, 14c' and 14d show the failure mode of the GFRP reinforced beams which is a step-like, shear type crack that follows the masonry joints. After the midspan initial micro-cracks, a crack starts at the support, goes through the FRP-block interface and then it follows the mortar joints. The FRP strips remain intact. In the particular case of beam B 3-1, a crack starts from the support first by the composite debonding and then cracks propagates from the lower face in the span of constant moment (Fig.14c). In all the other cases the debonding was observed at the end of testing. Concerning the debonding of the composite strip (Fig.14e) from the stone surface, the observation of the interface after failure shows that cracking goes through the stone in the vicinity of the interface.

Fig.13 shows four diagrams of the average values of failure load for the beams B 1, B 2, B 3 and B 4 (load-deflection diagrams). It can be noted that experimental results show a linear behaviour for a little deflection below $0.1 \mathrm{~mm}$ and a non-linear behaviour above $0.1 \mathrm{~mm}$ with crack propagation. It can be noted also (see Tab.4) that the reinforcement with 4 layers FRP increases about 4 times the failure load and confirms the FRP contribution to increase the tensile stress of masonry structures. By comparing the failure load of beams group B 2 (beams reinforced with 2 layers) with B 4 (beams reinforced with 4 layers), we observe an increase of the failure load by about $30 \%$.

As presented in Fig.13, a change of slope appears in curves B 2, B 3 and B 4 at a deflection between $0.2 \mathrm{~mm}$ and $0.4 \mathrm{~mm}$. This decreasing of stiffness is the effect of micro-cracks in the masonry under local tension at midspan on the lower face. Above 0.4 , the remaining part of the curves describes a second failure corresponding to propagating macro-cracks starting close to the support. So, the first failure to be considered for the modeling of the reinforcement corresponds to a state where the maximum tensile stress reaches the tensile strength in the masonry at midspan observed for a deflection equal to $0.2 \mathrm{~mm}$.

\section{Finite Element modeling}

The objective of this section is to develop a Finite Element (FE) model in order to predict the structural behaviour of stone masonry structure reinforced with GFRP. The finite element model is shown in Fig.15.

The material properties used for the analysis were based on the results of laboratory tests shown previously in Tab.2.

\subsection{Loading and boundary conditions of the FE model}

The numerical analysis herein is a three dimensional-nonlinear finite element analysis of the experimental set-up by the means of the commercial FE program ABAQUS. Fig.15 shows a typical three-dimensional solid model containing the geometry, boundary conditions, the load and the mesh used in this study.

The loading and boundary conditions are designed to simulate the experimental behavior of the tested beams. The weight of the beam wasn't considered since the deflection recording began when the beam was already overturned and the deflection due to the weight wasn't recorded.

During analysis, a vertical displacement is imposed at the upper side of the beam. The model is supported and restrained from out of the loading plan translation, using support (roller) lines. Full bond is assumed between FRP and masonry. 


\subsection{Constitutive model}

Bricks and mortar are geomaterials, which are commonly described by Coulomb failure criterion. Nevertheless, the numerical treatment of Coulomb yield surfaces can provoke numerical problems. Therefore, for the numerical analysis performed in this section, the stone blocks and mortar joints are considered to obey to a Drucker-Prager (DP) criterion, with associate flow rule. This approach brings considerable advantages from the computational point of view due to its robustness and convergence. It is worth mentioning that both Drucker-Prager and Coulomb criteria might not be appropriate to describe the mechanical behavior of a geomaterial, in general. Plasticity theory itself might be also inadequate to take into account the detailed behavior of a geomaterial and especially in the shear-extension regime, i.e. at low confinement. However, they seem to be reasonable modeling choices given the few parameters needed to define these criteria and their evolution (e.g. hardening). Notice that Drucker-Prager is a criterion that it is often used in soil and rock mechanics at low confinements (see for example Davis \& Salvadurai [25]). For a further discussion on this topic we refer to I.Stefanou et al. [26]). The yield surface of DP is expressed as follows:

$$
F=q-p \tan \beta-d \quad \text { Eq.(1) }
$$

Where

$p=\frac{1}{3} \operatorname{tr} \sigma$ is the mean stress,

$\boldsymbol{q}=\sqrt{\frac{3}{2} \operatorname{tr} s: s}$ the shear stress intensity, $\boldsymbol{s}=\boldsymbol{\sigma}-\boldsymbol{p I}$ is the deviatoric stress tensor,

$d$ and $\beta$ are the DP criterion parameters, which can be expressed in terms of the Coulomb friction angle and cohesion (see I.Stefanou et al. [26]).

The choice of the appropriate model [27] to be used depends largely on the analysis type, the kind of material, the experimental data available for calibration of the model parameters, and the range of mean stress values that the material is likely to experience.

The accuracy with which the DP criterion can fit these test data is limited by the fact that it assumes linear dependence of the shear stress intensity with the mean stress. Moreover, numerical problems might arise in the case of the DP yield surface due to the non-differentiability of the failure surface $F$ at $p=0$. In order to avoid such numerical problems and to better capture the mechanical behavior at shear-extensional regime (low mean stress) a regularized version of the DP criterion is often used in practice. In Figure 18 we present this regularized version of DP, which is often called hyperbolic DP in the literature. The yield function of the hyperbolic DP criterion is given by the following equation:

$$
F=\sqrt{l_{0}^{2}+q^{2}}-p \tan \beta-d^{\prime} \quad \text { Eq.(2) }
$$

Where

$l_{0}=\left.d^{\prime}\right|_{0}-\left.p_{t}\right|_{0} \tan \beta$,

$\mathrm{I}_{0}$ is equivalent to a cohesion,

$\left.d^{\prime}\right|_{0}$ is the initial value of $d^{\prime}$,

$\left.p_{t}\right|_{0}$ is the initial hydrostatic tension strength of the material $\approx \frac{d^{\prime}}{2 \tan \beta}$

and $\mathrm{d}^{\prime}$ is the cohesion of the material.

\subsection{Materials properties for the FE analysis}

The experimental results were used to define the model input parameters. The stone block and the mortar are modeled as isotropic materials, using respectively a Young's modulus of $17 \mathrm{GPa}$ and 1.2 GPa, and respectively a Poisson's ratio of 0.20 and 0.30 . 
In the purpose to measure the influence of hydrostatic pressure on the properties and thus, to conclude on the yield criterion to be adopted for materials characterization, the previous compressive and tensile tests (Fig. 6) presented in section 2.2 were used leading to different states of hydrostatic pressure [28]. The idea of using compression tests and flexural tensile tests results from the works of Chataigner [29] and Wang [30].

Linear fittings were performed afterwards as shown in Fig. 16. This gives the identified cohesion and friction angle presented in Tab. 5.

In F.E. modelling, DP material model is defined for the stone and the mortar using the friction angle $\beta$, initial tension strength $\left.p_{t}\right|_{0}$ and hardening curves for different strain rates. For the latter, a light hardening was adopted starting from the yield tensile strength with a slight slope. Calculation parameters are summarized in Tab.5.

Masonry is brittle in tension and ductile in compression. Furthermore, experimental tests show that the composite remains intact after beams failure, this is explained by the high tensile strength of composite, which is 370 times higher than the tensile strength of the mortar joint (Tab. 2). The experimental tests show also that the masonry beams strengthened with GFRP strips behave like the over reinforced concrete beams under positive bending where the lower reinforcement remains elastic and where the upper concrete exhibits ductility under compression. In the framework of prestressed and reinforced concrete modeling in the serviceability state, the crack opening is generally limited by a positive strain threshold. In the same context, our numerical analysis is stopped when the tensile stress reaches the tensile strength of masonry in mortar. The model was valid until the field of principal stress reaches the tensile strength of $0.26 \mathrm{MPa}$. This threshold corresponds to the first failure observed between $0.2-0.4 \mathrm{~mm}$.

The GFRP are assumed elastic materials as the elastic yield is not reached here (since the FRP strips weren't affected when masonry beams failed). Typically, the fibers show no ductility, so the stressstrain behavior of most FRP's can be taken as linear elastic to failure [31].

Furthermore, the composite is assumed perfectly bonded to the masonry. This simplified hypothesis can describe the peeling-off failure mode through the analysis of stresses in masonry but in the vicinity of the composite. This failure mode corresponds to a debonding of the composite with a rock material which still bonded in it as observed in Fig. 14e. The masonry remains always the weaker element of the interface due to a higher strength of the epoxy.

\section{Comparison between numerical and experimental results}

Fig.17 presents the total load as function of mid-span deflection for beams B 1 to B 4.The effect of plasticity appears through a global non linear structural behavior. It can be noted that the FRP reinforcement contributes to a slight increasing of the initial global stiffness, as expected. In the framework of the elastoplastic analysis, the effect of FRP is more noticeable on the bearing capacity. The analysis of the failure mode revealed that the weakest part of the structural system was the mortar joint where the tensile strength in the stone-mortar interface is reached. This is in accordance with the experimental tests. The structural behavior is stopped at a step corresponding to the maximum tensile stress in the stone-mortar interface reaching its limit of $0.26 \mathrm{MPa}$ (see Tab.2). Because of the brittleness of masonry in tension, the process was stopped at this step. It is noted also that the longitudinal tensile strength of the composite strip is not reached in any of the simulations performed.

Fig.17 presents a comparison between numerical and experimental results. The discontinuous vertical line corresponds to the step at which the maximum of the field of principal tensile stresses defined in all joints reaches its maximum value of $0.26 \mathrm{MPa}$.

As presented in Fig.17 the present numerical model reproduces the experimental tendency. It can be noted that the numerical analysis show an increasing of the initial stiffness within the strengthening. 
Furthermore, the numerical analysis predicts an increasing of the numerical failure load from $3.8 \mathrm{kN}$ for the un-reinforced beam to $9.1 \mathrm{kN}$ for the beam strengthened with 2 layers and to $11 \mathrm{kN}$ for the beam strengthened with 4 layers. The numerical failure load is defined as the applied load corresponding to a local tensile strength reached in masonry. For the strengthened beams, these failure loads remain in safety when comparing them to the experimental ones as depicted in Tab.6. This indicates that this simplified numerical approach is suitable to estimate the bearing capacity of the strengthened structures. Moreover, we notice an increase of the failure load when the reinforcement is increased. The experimental results of the failure deflection obtained for $B$ and $B$ 4 can be explained as follow : the reinforced beam doesn't fail when the mortar reach its tensile strength because crack propagation continues through the stone block until failure.

Fig.18 presents the shear strain field. This strain is concentrated in the horizontal joint between blocks and the vertical joints near the supports. This is in agreement with the failure mode observed experimentally and depicted in figure 14 in which we can see cracks appearing in the aforementioned joints. Furthermore, numerical results are in agreement with the relative sliding observed between blocks (see Fig.14b).

\section{Conclusion}

The above-discussed results reveal interesting aspects of using economic hand-made GFRP strips in the reinforcement of masonry structures. In this paper four samples of reinforced stone beams have been tested. Their structural behaviour has been investigated and the results of these investigations have shown that the idea of developing reinforced stone structures by composites in a similar way to reinforced concrete structures is promising.

A 3D nonlinear numerical model using the finite element commercial package, ABAQUS, has been developed to predict the flexural load capacity and structural stiffness of beams. Based on the work described in this paper, the following conclusions are drawn:

- All strengthened beams exhibited a higher load capacity and a more ductile behavior, compared with the un-reinforced beams.

- The analysis of the failure mode revealed that the weakest part of the structural system was, as expected, the mortar joint.

- There was an acceptable agreement between experimental and numerical results.

- The Drucker-Prager criterion in his hyperbolic form was suitable for the FE modelling analysis of masonry structures.

Concerning the design of masonry structures reinforced by FRP, the authors think that the present experiments give a reliable database for the calibration of a numerical model.

\section{References}

[1] Heyman J. The stone skeleton: structural engineering of masonry architecture. Cambridge University Press; 1997.p. 172.

[2] De Felice G. Assessment of the load-carrying capacity of multi-span masonry arch bridges using fibre beam elements. Eng.Struct. 2009;31:1634-47.

[3] Tao Y, Stratford TJ, Chen JF. Behaviour of a masonry arch bridge repaired using fibre-reinforced polymer composites. Eng.Struct. 2011;33:1594-606.

[4] OmikrineMetalssi O, Douthe C, Presepi M, Mondardini L, Brocato M. Experimental study on reinforced stone beams. Eng.Struct. 2013;54:1-8]

[5] Kiss RM, Kollar LP, Jai J and Krawinkler H. FRP Strengthened Masonry Beams. Part I - Model. Journal of Comp. Mat.2002;36(5):521-536

[6] Ehsani MR, Saadatmanesh H, Abdelghanyl H. and Elkafrawy W. Flexural behavior of masonry walls strengthened with composite fabrics. In: Nanni A and Dolan CW (eds.),In: Proceedings of the International 
Symposium on FRP Reinforcement for Concrete Structures. ACl - American Concrete Institute, 1993. p. 497507.

[7] SchweglerG. Masonry construction strengthened with fiber composites in seismically endangered zones. In: Duma G (ed.),In: Proceedings of the Tenth European Conference on Earthquake Engineering. EAEE-European Association for Earthquake Engineering. Volume 3, 1994. p. 2299-2303.

[8] Ehsani MR. Seismic retrofitting of masonry structures with composite materials: Research and field application. In: Applied Mechanics in the Americas. Volume III, 1995.p. 383-390.

[9] Triantafillou TC. Innovative strengthening of masonry monuments with composites. In: El-Badry M.M. (ed.), In: Proceedings of the Second International Conference on Advanced Composite Materials in Bridges and Structures. CSCE - Canadian Society for Civil Engineering, 1996.p. 473-480.

[10] Schwegler $G$ and Kelterborn P. Earthquake resistance of masonry structures strengthened with fiber composites. In: Proceedings of the Eleventh World Conference of Earthquake Engineering, 1996. IAEE International Association for Earthquake Engineering. Disc 3, article 1460.

[11] Triantafillou TC. Strengthening of masonry structures using epoxy-bonded FRP laminates. J. Compos.Constr.1998;2:96-104.

[12] Theriault $M$ and Benmokrane B. Effects of FRP reinforcement ratio and concrete strength on flexural behavior of concrete beams. J. Compos. Constr., 1998;2(1):7-16.

[13] Abdalla HA. Evaluation of deflection in concrete members reinforced with FRP bars. Compos.Struct.2002;56:63-71.

[14] Limam O, Foret G, Ehrlacher A. RC two-way slabs strengthened with CFRP strips: experimental study and a limit analysis approach. Compos. Struct. 2003;60(4):467-471.

[15] Saikia B, Kumar P, Thomas J, Rao KSN and Ramaswamy A. Strength and serviceability performance of beams reinforced with GFRP bars in flexure. Constr. Build. Mater. 2007;21(8):1709-1719.

[16] Lourenço, P.B. Analysis and restoration of ancient masonry structures: guidelines and examples. Proceedings of Innovative Materials and Technologies for Construction and Restoration, Italy, 2004: 23-41.

[17] Chalhoub M. Apports des méthodes d'homogénéisation numériques à la classification des massifs rocheux fracturés. Engineering Sciences. Ecole Nationale Supérieure des Mines de Paris, 2006. In french.

[18] Chalhoub M. Massifs rocheux - Homogénéisation et classification numériques. Presses des MINES, 2010.

[19] Mestat P. Lois de comportement des géomatériaux et modélisation par la méthode des éléments finis. Collection "Etudes et recherche des laboratoires des Ponts et Chaussées ", série Géotechnique, 1993, ISSN $1157-3910$.

[20] Moropoulou A, Bakolas A and Anagnostopoulou S. Composite materials in ancient structures. Cem \& Concr. Compos 2005;27:295-300.

[21] Labesse O. Specific use of natural hydraulic lime, Nantes 2005 available on www.openarchive.icomos.org, in french.

[22] NF EN 1015-2 Methods of test for mortar for masonry - Part 2: bulk sampling of mortars and preparation of test mortars.

[23] NF EN 1015-3: Methods of test for mortar for masonry - Part 3: determination of consistence of fresh mortar (by flow table).

[24] ISO 527-4: 1997: Plastics - Determination of tensile properties - Part 4: Test conditions for isotropic and orthotropic fibre-reinforced plastic composites.

[25] Davis RO., Selvadurai APS. Plasticity in Geomechanics, Cambridge University Press, 2002.

[26] Stefanou I, Sab K, Heck JV. Three dimensional homogenization of masonry structures with building blocks of finite strength: A closed form strength domain. International Journal of Solids and Structures, Volume 54, February 2015, Pages 258-270.

[27] ABAQUS. ABAQUS Analysis user's manual, version $6.9 ; 2004$.

[28] Radfar S, Foret G, Saeedi N, Sab K. Simulation of concrete cover separation failure in FRP plated RC beams. Constr. Build. Mater.2012;37:791-800.

[29] Chataigner S. Conception et dimensionnement d'un ancrage de hauban plat en matériaux composites. PhD thesis (in french), ENPC, 2008.

[30] Wang W. Towards an improved understanding of strength and anisotropy of cold compacted powder. PhD thesis, Drexel University, 2007.

[31] Shrive NG. The use of fiber reinforced polymers to improve seismic resistance of masonry. Constr. Build. Mater.2006;20: 269-277. 